\title{
Low-Dose Aspirin Use Among African American Older Adults
}

\author{
Mohsen Bazargan, PhD, Cheryl Wisseh, PharmD, MPH, TTS, \\ Edward Adinkrah, MBChB, BSc, Shanika Boyce, MD, FAAP, MPH, \\ Ebony O. King, MD, and Shervin Assari, MD, $M P H$
}

Objectives: Existing epidemiologic information shows disparities in low-dose aspirin use by race. This study investigates the frequency, pattern, and correlates of both self- and clinician-prescribed low-dose aspirin use among underserved African Americans aged 55 years and older.

Methods: This cross-sectional study conducted a comprehensive evaluation of all over-the-counter and prescribed medications used among 683 African American older adults in South Central Los Angeles, California. Correlation between use of low-dose aspirin and sociodemographic variables, health care continuity, health behaviors, and several major chronic medical conditions were examined. In addition, the use of low-dose aspirin as self prescribed versus clinician prescribed was examined. Multivariate logistic regression was performed to examine correlates of low-dose aspirin use.

Results: Overall, 37\% of participants were taking low-dose aspirin. Sixty percent of low-dose aspirin users were taking low-dose aspirin as self prescribed and $40 \%$ were taking it as prescribed by a clinician. Major aspirin-drug interactions were detected in $75 \%$ of participants who used low-dose aspirin, but no significant differences in aspirin-drug interactions were found between those who used aspirin as self prescribed and those who used it as clinician prescribed. No negative association between being diagnosed with gastrointestinal conditions and aspirin used was detected. Being diagnosed with diabetes mellitus or a heart condition was associated with higher use of aspirin. However, only $50 \%$ with high risk of cardiovascular took prescribed (38\%) or self-prescribed (62\%) low-dose aspirin. One third of participants aged 70 years and older with low risk of cardiovascular were using aspirin.

Conclusions: Among underserved African-American middle-aged and older adults, many who could potentially benefit from aspirin are not taking it; and many taking aspirin have no indication to do so and risk unnecessary side effects. Compared with non-Hispanic Whites, African Americans are more likely to be diagnosed with diabetes, hypertension, and heart conditions at earlier stages of life; as a result, the role of preventive intervention, including safe and appropriate use of low-dose aspirin among this segment of our population, is more salient. Interventional studies are needed to promote safe and effective use of lowdose aspirin among underserved African-American adults. ( $\mathrm{J}$ Am Board Fam Med 2021;34:132-143.)

Keywords: African Americans, Aging, Aspirin, Cardiovascular Diseases, Cross-Sectional Studies, Logistic Models, Los Angeles, Minority Health, Preventive Health Services, Primary Prevention, Secondary Prevention

\section{Introduction}

The United States Preventive Services Task Force and other clinical guidelines have recommended

This article was externally peer reviewed.

Submitted 30 June 2020; revised 28 July 2020; accepted 29 July 2020.

From the Department of Family Medicine, Charles R. Drew University of Medicine and Science, Los Angeles, CA (MB, CW, SA); Department of Family Medicine, David Geffen School of Medicine, University of California-Los Angeles (MB); Department of Clinical Pharmacy Practice, School of Pharmacy and Pharmaceutical Sciences, University of California at Irvine, Los Angeles, CA (CW); Department of Public Health, Charles R. Drew University of Medicine and low-dose daily aspirin for primary and secondary prevention of cardiovascular disease. ${ }^{1,2}$ These recommendations are based on the well-established efficacy

Science, Los Angeles, CA (EA); Department of Pediatrics, Charles R. Drew University of Medicine and Science, Los Angeles, CA (SB); Department of Family Medicine, Kaiser Permanente, Los Angeles, CA (EOK).

Funding: This study was supported by the Center for Medicare and Medicaid Services (CMS) award number 1H0CMS331621 (PI: M. Bazargan). SB, AE, and CW were supported by the National Institute of Minority Health and Health Disparities (NIMHD) under the award number R25 MD007610 (PI: M. Bazargan). Additionally, this study was supported by the NIMHD award number U54 MD007598 
of low-dose aspirin in reducing cardiovascular disease (CVD) risk. ${ }^{3,4}$ Several systematic reviews and metaanalyses have also documented the effectiveness of long-term low-dose aspirin in preventing several types of cancer and improving survival after a cancer diagnosis. ${ }^{5-9}$ However, recent data suggest that the role of aspirin in primary prevention should be reassessed. ${ }^{10-14}$ For example, studies have documented that while aspirin therapy is underused by those at high risk for cardiovascular disease, it is also overused by those at low risk for cardiovascular disease, and by those for whom the risk of bleeding outweighs the potential benefit of cardioprotection. ${ }^{15-17}$ More specifically, upper gastrointestinal (GI) bleeding and hemorrhagic stroke are major adverse effects of long-term use of low-dose aspirin. ${ }^{18}$ For these reasons, the 2019 American College of Cardiology/American Heart Association (ACC/AHA) Guideline on the Primary Prevention of CVD recommends that low-dose aspirin be considered for primary prevention of CVD in adults 40 to 70 years of age who are at higher risk for atherosclerotic cardiovascular disease, but only for those who are not at risk of bleeding. ${ }^{19,20}$

CVD is the primary cause of death in the United States in both men and women. According to the Centers for Disease Control and Prevention, 1 in every 4 deaths is due to CVD. ${ }^{21}$ Among racial groups, non-Hispanic Blacks are 20\% more likely to die from heart disease than non-Hispanic Whites. ${ }^{22}$ Older African Americans tend to have higher rates of cardiometabolic diseases such as hypertension and diabetes mellitus compared with their white counterparts. ${ }^{23}$ The most recent report published by the Centers for Medicare and Medicaid Services shows that $71 \%$ of older non-Hispanic African Americans have hypertension, $41 \%$ have diabetes, and $19 \%$ have heart failure. ${ }^{24}$ The comparable figures for older non-Hispanic Whites are 60\% (hypertension), 25\% (diabetes), and 15\% (heart

(PI: J. Vadgama) and by National Institutes for Health (NIH) National Center for Advancing Translational Science (NCATS) UCLA CTSI Grant Number UL1TR001881 (PIs: S. Dubinett and R. Jenders). This study contents are solely the responsibility of the authors and do not necessarily represent the official views of the CMS and NIH.

Conflict of interest: None.

Corresponding author: Mohsen Bazargan, $\mathrm{PhD}$, Department of Family Medicine, Charles R. Drew University of Medicine and Science, Los Angeles, California (E-mail: mohsenbazargan@ cdrewu.edu). failure). ${ }^{24}$ Furthermore, more than $35 \%$ of older African-American adults have comorbid hypertension and diabetes mellitus. ${ }^{25}$ Yet only $39 \%$ and 53\% of African-American older adults with diabetes mellitus and hypertension exhibit glycemic control and blood pressure control, respectively. ${ }^{26,27}$

However, the existing epidemiologic literature demonstrates disparities in low-dose aspirin use by race and ethnicity, ${ }^{28-31}$ specifically, suboptimal preventive aspirin use among African-American adults. ${ }^{32}$ Thus, promotion of safe use of low-dose aspirin in low-income, middle-aged and older AfricanAmerican adult communities may be an effective step toward reduction of racial disparities in CVD. However, studies documenting the correlates of lowdose aspirin use in this population are lacking, and consequently, there is a paucity of interventions that promote appropriate and effective use of low-dose aspirin among underserved African-American adults. Therefore, our study aims to investigate the sociodemographic and health factors that characterize economically disadvantaged middle-aged and older African-American adults in South Los Angeles, CA based on low-dose aspirin use. Such information may enable health care providers to better guide AfricanAmerican communities' use of low-dose aspirin to maximize its benefits. To the best of our knowledge, this is the only study that has been conducted among underserved older African American adults to examine correlates of selfand clinician-prescribed low-dose aspirin and to investigate aspirin-drug interactions.

\section{Materials and Methods}

This study was a cross-sectional survey of middleaged and older African-American adults performed in Service Planning Area. Spanning 4752 square miles, Los Angeles County is divided into 8 geographical SPAs. This enables the Department of Public Health to plan and implement targeted public health and clinical programs based on the needs of each area. ${ }^{33}$ South SPA, with a population of approximately 1,048,734, has the highest density of African Americans in Los Angeles County. Of the 8 SPAs, the South SPA has the highest rates for major chronic conditions among older adults. ${ }^{34}$ More specifically, CVD, stroke, and diabetes mellitus are among top age-adjusted causes of death in South SPA. ${ }^{33}$ Participants in this study were sampled from 16 predominantly African-American 
churches and 11 senior housing apartment units and public housing projects. Church leaders and housing apartment managers facilitated and encouraged participation of the individuals in their communities. Participants were eligible if they identified as African American or Black, were 55 years or older, English speaking and could complete an interview in English. However, we did not encounter any participants with language barriers. Less than $5 \%$ of individuals who were approached, refused to participate. Two trained health professional research associates conducted the face-toface interviews in a private room at participating sites. Structured interviews were conducted to collect data on demographic factors, socioeconomic status, health status, health care utilization, health behaviors, as well as a comprehensive examination of over-the-counter and prescription drug use. The study protocol was approved by the institutional review board of Charles R. Drew University of Medicine and Science. All participants signed a written informed consent before enrollment in the study.

\section{Measurements}

\section{Sociodemographic Covariates}

Age, educational attainment, and living arrangement were the covariates in this study. Age and educational attainment were operationalized as interval variables (years of schooling). Higher scores indicated more years of education.

\section{Living Arrangement}

Participants' living arrangement was a single item. We asked participants whether they lived alone or if there was any other member of the family such as partner or spouse who lived with them $(1=$ lived alone; $0=$ lived with family member).

\section{Financial Strain}

Financial strain was measured using 5 items. Participants were asked: In the past 12 months 1) how frequently were you unable to buy the amount of food your family should have? 2) How frequently were you unable to buy the clothes you feel your family should have? 3) How often were you unable to pay your rent or mortgage? 4) How frequently were you unable to pay your monthly bills? and 5) How often were you unable to make ends meet? Items were on a 5-level response scale ranging from 1 (never) to 5 (always). A total "financial difficulty" score was calculated, with the average score of 5 items, ranging from 1 to 5 . A high score was indicative of higher financial difficulty. These items are consistent with Pearlin's list of chronic financial difficulties of low socioeconomic status (SES) individuals (Cronbach $\alpha=0.92){ }^{35}$

\section{Continuity of Medical Care}

Continuity of Medical Care was measured using 3 items. Participants were asked to report 1) what type of place they usually visit to receive medical care (a private doctor's office/private medical group vs other settings), 2) whether they usually go to the same place for medical care, and 3) whether they are usually attended by the same health provider when they received medical care. A higher score indicates more continuity of care.

\section{Smoking Behavior}

Participants were asked how they describe their cigarette smoking habits. Response items to this question was never smoked, previously a smoker (exsmoker), and current smoker.

\section{Major Chronic Conditions}

Participants were asked to report whether they have been diagnosed with the following conditions: high blood pressure, diabetes mellitus, heart conditions, asthma or bronchitis, stroke, and cancer. In addition, participants were asked to report whether they have been diagnosed with GI conditions.

\section{Aspirin Use}

Using a comprehensive evaluation of all medications used, we built a 3-level categorical variable (outcome) that was reflective of 1) not using lowdose aspirin, 2) taking over-the counter (OTC) low-dose aspirin, and 3) taking prescribed low-dose aspirin. Of note, low-dose aspirin use was selfreported and characterized either as prescribed by a clinician or primary health care provider or as self prescribed (ie, the participant took OTC aspirin of his/her own volition). Low-dose aspirin was defined as an aspirin dosage $\leq 100 \mathrm{mg}$ no more than once a day.

\section{Other Medication Use}

Medication use was assessed using the drug inventory method. Participants were asked to bring all OTC and prescription $(\mathrm{Rx})$ medications that were taken within 2 weeks before the interviews. The 
interviewer transcribed from the container label the name of the medication, strength of the drug, expiration date, instructions, special warnings, provider information, etc. The medication assessment of this study employed the methodology established by Sorensen and colleagues, ${ }^{36}$ which was utilized by our research team previously. ${ }^{37-39}$

\section{Aspirin-Other-Drug Interactions}

IBM Micromedex Web Application Access was used to classify aspirin drug interactions. Micromedex is a copyrighted database of IBM (Armonk, NY). ${ }^{40}$ In a study that compared 5 common drug-drug interaction software programs, IBM Micromedex received high scores in accuracy of detecting clinically important drug-drug interactions and in overall comprehensiveness. ${ }^{41}$ Individual drug interaction reports were generated for each participant by a team of pharmacists and physicians. Aspirin-drug interactions were a 5-level categorical variable: 1 ) major interaction, 2) moderate interaction, 3) mild interaction, 4) no interaction, and 5) contraindicated. The reports were categorized into 2 groups: no major interaction (0) and at least 1 major interaction (1).

\section{Data Analysis}

The analysis consisted of 3 parts. The first part was a descriptive analysis, which reported means (SD) for the continuous measures, such as age (years), and frequency and percentages for the categorical variables, such as aspirin use, OTC, or aspirin-drug interactions. Chi-squared and independent t-test were used to compare participants who used lowdose aspirin with those who did not. An additional chi-squared test and analysis of variance were employed to compare the following 3 groups: individuals who did not use low-dose aspirin, individuals taking self-prescribed low-dose aspirin, and individuals taking clinician-prescribed low-dose aspirin. Finally, multivariate logistic regression was performed to examine correlates of low-dose aspirin use.

In addition, a series of binary logistic regressions were conducted to examine correlates of low-dose aspirin use. The first model includes demographic variables (ie, age, gender, education, and living arrangement), financial strains, smoking status, continuity of care, being diagnosed with diabetes mellitus, heart conditions, stroke, GI conditions, and major drug-aspirin interactions. The second model substitutes diabetes mellitus, heart conditions, and stroke with a single variable that reports the sum (number) of these 3 chronic conditions. Finally, we employed multinomial logistic regression to compare self-prescribed and clinician-prescribed aspirin use with no aspirin use. $\mathrm{P}<.05$ was considered significant.

\section{Results}

Table 1 reports the characteristics of the study sample. This study recruited 740 African-American adults aged 55 years and older. Six hundred eightythree participants between the ages of 55 and 96 years (mean, $71.8 \pm 8.3$ years) were included and 57 participants were excluded. More specifically, 32 (4.3\%) participants had an incomplete survey record, and 25 (3.4\%) were taking a higher dose of aspirin $(\geq 325 \mathrm{mg}$ ) for pain management. More than $35 \%$ of the participants were 75 years of age or older, and $64 \%$ of the participants were women. Only $15 \%$ of the sample were currently married or lived with a companion. More than $35 \%$ of our sample reported having a high school diploma, $25 \%$ reported 0 to 11 years of education. Thirty-

Table 1. Descriptive Characteristics $(n=683)$

\begin{tabular}{|c|c|c|}
\hline & $\mathrm{n}$ & $\%$ \\
\hline \multicolumn{3}{|l|}{ Gender } \\
\hline Female & 439 & 64.3 \\
\hline Male & 244 & 35.7 \\
\hline \multicolumn{3}{|l|}{ Age, years } \\
\hline 55 to 64 & 106 & 15.5 \\
\hline 65 to 74 & 337 & 49.3 \\
\hline$\geq 75$ & 240 & 35.1 \\
\hline \multicolumn{3}{|l|}{ Education } \\
\hline No high school diploma & 168 & 24.6 \\
\hline High school diploma & 242 & 35.4 \\
\hline Some college or college degree & 273 & 40.0 \\
\hline \multicolumn{3}{|l|}{ Living alone } \\
\hline No & 276 & 40.4 \\
\hline Yes & 407 & 59.6 \\
\hline \multicolumn{3}{|l|}{ Smoking behaviors } \\
\hline Current smoker & 142 & 20.8 \\
\hline Past smoker & 214 & 31.4 \\
\hline \multirow[t]{2}{*}{ Never smoked } & 326 & 47.8 \\
\hline & & Mean $\pm \mathrm{SD}$ \\
\hline Age (years: 55 to 96 ) & & $71.8 \pm 8.3$ \\
\hline Education attainment (1 to 16 ) & & $12.8 \pm 2.2$ \\
\hline Financial strains ( 1 to 5 ) & & $1.8 \pm 1.1$ \\
\hline Continuity of care (0 to 3 ) & & $2.5 \pm 0.66$ \\
\hline Major chronic conditions (1 to 6 ) & & $1.8 \pm 0.9$ \\
\hline
\end{tabular}


four percent of participants reported being diagnosed with diabetes mellitus, $14 \%$ had stroke, and $29 \%$ had heart conditions. Participants were taking an average of $5.8(\mathrm{SD}=3.02) \mathrm{Rx}$ medications; 1.12 $(\mathrm{SD}=1.9)$ OTC medication and $7.2 \quad(\mathrm{SD}=34.0)$ OTC and Rx medications. Table 2 reports major aspirin-drug interactions among all participants. The top 3 major aspirin-drug interactions occurred with hydrochlorothiazide (34\%), metformin (23\%), and furosemide (16\%).

\section{Low-Dose Aspirin Use}

Table 2 reports that $37 \%(n=254)$ of participants were taking low-dose aspirin. Of the 254 individuals who were taking low-dose aspirin, $60 \%$ were taking it as self prescribed and $40 \%$ as clinician prescribed. A potentially major aspirin-drug interaction was observed in $75 \%$ of the 254 participants using low-

Table 2. Low-Dose Aspirin Use and Drug-Aspirin Interactions $(\mathrm{n}=\mathbf{6 8 3})$

\begin{tabular}{|c|c|c|c|}
\hline & $\mathrm{n}$ & $\%$ & $\begin{array}{l}\text { Valid } \\
\%\end{array}$ \\
\hline \multicolumn{4}{|l|}{ Low-dose aspirin use } \\
\hline No & 429 & 62.8 & 62.8 \\
\hline Yes & 254 & 37.2 & 37.2 \\
\hline \multicolumn{4}{|l|}{$\begin{array}{l}\text { Prescribed versus self-prescribed } \\
\text { aspirin use }\end{array}$} \\
\hline OTC & 152 & 22.3 & 59.8 \\
\hline $\mathrm{Rx}$ & 102 & 14.9 & 40.2 \\
\hline No low-dose aspirin used & 429 & 62.8 & \\
\hline \multicolumn{4}{|l|}{$\begin{array}{l}\text { Top } 5 \text { potentially major aspirin- } \\
\text { drug interactions }\end{array}$} \\
\hline Hydrochlorothiazide & 83 & & 33.7 \\
\hline Metformin & 58 & & 22.8 \\
\hline Furosemide & 49 & & 15.7 \\
\hline Glipizide & 32 & & 12.6 \\
\hline $\begin{array}{l}\text { Hydrochlorothiazide }+ \\
\text { triamterene }\end{array}$ & 25 & & 9.8 \\
\hline \multicolumn{4}{|c|}{$\begin{array}{l}\text { Potential major aspirin-drug interactions (among non-aspirin } \\
\text { users) }\end{array}$} \\
\hline No interaction & 146 & 34.1 & 34.1 \\
\hline One major interaction & 161 & 37.6 & 37.6 \\
\hline Two major interactions & 81 & 18.9 & 18.9 \\
\hline \multirow[t]{2}{*}{ Three or more major interactions } & 40 & 9.3 & 9.3 \\
\hline & \multicolumn{3}{|c|}{ Mean \pm SD } \\
\hline $\begin{array}{l}\text { Frequency of potentially major } \\
\text { aspirin-drug interaction for } \\
\text { aspirin users }\end{array}$ & \multicolumn{3}{|c|}{$1.3 \pm 1.08$} \\
\hline $\begin{array}{l}\text { Frequency of potentially major } \\
\text { aspirin-drug interactions for } \\
\text { non-aspirin users }\end{array}$ & \multicolumn{3}{|c|}{$1.1 \pm 1.06$} \\
\hline
\end{tabular}

OTC, over-the counter. dose aspirin. Of all participants, 28\% were taking low-dose aspirin despite having a potentially major aspirin-drug interaction (Table 2). While $66 \%$ of aspirin nonusers could potentially have experienced a major drug-aspirin interaction if they had used aspirin, $34 \%$ of aspirin nonusers would not have had a major aspirin drug interaction if they had used aspirin. Thus, comparing aspirin users with nonusers, nonusers would have experienced fewer drug-aspirin interactions compared with their aspirin-using counterparts $(66 \%$ vs $75 \% ; \mathrm{P}<.01)$. Nineteen percent (81) of aspirin users reported being diagnosed with GI-related conditions. In addition, 23\% (100) and $31 \%$ (133) of nonaspirin users reported being diagnosed with heart conditions or mellitus diabetes, respectively.

\section{Bivariate Analysis}

As demonstrated in Table 3, men, younger older adults, and current and past smokers, were less likely to use low-dose aspirin compared with women, the old-old ( $\geq 75$ years), and nonsmokers. In addition, participants who were diagnosed with diabetes mellitus and heart conditions were more likely to use aspirin than their counterparts. Finally, the old-old, nonsmokers, those with less financial strain, and those who self reported better continuity of care were more likely to use self-prescribed lowdose aspirin than their counterparts.

\section{Multivariate Logistic Regression}

Correlates of Low-Dose Aspirin Use

Table 4 shows that controlling for all relevant variables, only 2 variables were statistically significant: participants who had been diagnosed with diabetes mellitus (odds ratio $[\mathrm{OR}]=1.51 ; 95 \% \mathrm{CI}, 1.07$ 2.14) or heart conditions ( $\mathrm{OR}=2.24$; $95 \% \mathrm{CI}, 1.55$ $3.23)$ were more likely to use low-dose aspirin. It is important to note that several variables including major drug-aspirin interactions, GI-related symptoms, and age were not associated with low-dose aspirin use in the binary multivariate logistic models (Table 4).

Comparing Correlates of Low-Dose SelfPrescribed and Physician-Prescribed Aspirin Use with No Aspirin Use

Multinomial logistic regression shows that participants with diabetes mellitus were more likely to be prescribed low-dose aspirin. In other words, the odds of being prescribed low-dose aspirin by a 
Table 3. Prevalence of Low-Dosage Aspirin and Bivariate Correlations

\begin{tabular}{|c|c|c|c|c|c|c|}
\hline & \multicolumn{2}{|c|}{ Aspirin Used } & \multirow[b]{2}{*}{$P$} & \multirow{2}{*}{$\frac{\text { Clinician Prescribed }}{\mathrm{n}(\%)}$} & \multirow{2}{*}{$\frac{\text { Self Prescribed }}{\mathrm{n}(\%)}$} & \multirow[b]{2}{*}{$P$} \\
\hline & No, n (\%) & Yes, n\% & & & & \\
\hline \multicolumn{7}{|l|}{ Gender } \\
\hline Male & $165(68)$ & $79(32)$ & .052 & $34(43)$ & $45(57)$ & .507 \\
\hline Female & $264(60)$ & $175(40)$ & & $68(39)$ & $108(61)$ & \\
\hline Age, years & & & .03 & & & .0001 \\
\hline 55 to 64 (young-old) & $78(74)$ & $28(26)$ & & $24(86)$ & $4(14)$ & \\
\hline 65 to 74 (mid-old) & $210(62)$ & $127(38)$ & & $50(39)$ & $77(61)$ & \\
\hline$\geq 75$ (old-old) & $141(59)$ & $99(41)$ & & $28(28)$ & $71(72)$ & \\
\hline \multicolumn{7}{|l|}{ Living alone } \\
\hline No & $177(64)$ & $99(36)$ & .557 & $33(33)$ & $66(67)$ & .083 \\
\hline Yes & $252(62)$ & $155(38)$ & & $69(44)$ & $87(56)$ & \\
\hline \multicolumn{7}{|l|}{ Education } \\
\hline No high school diploma & $105(63)$ & $63(37)$ & .946 & $33(52)$ & $30(48)$ & .054 \\
\hline High school diploma & $154(64)$ & $88(36)$ & & $34(39)$ & $54(61)$ & \\
\hline Some college & $170(62)$ & $103(33)$ & & $35(34)$ & $69(66)$ & \\
\hline Smoking & & & .012 & & & .003 \\
\hline Current smoker & $102(72)$ & $40(28)$ & & $22(55)$ & $18(45)$ & \\
\hline Past smoker & $138(65)$ & $76(36)$ & & $38(49)$ & $39(51)$ & \\
\hline Never smoked & $188(58)$ & $138(42)$ & & $42(30)$ & $96(70)$ & \\
\hline \multicolumn{7}{|l|}{ GI conditions } \\
\hline No & $302(64)$ & $171(36)$ & .487 & $63(37)$ & $109(63)$ & .081 \\
\hline Yes & $127(61)$ & $81(39)$ & & $39(48)$ & $42(52)$ & \\
\hline Diabetes mellitus & & & .005 & & & .664 \\
\hline No & $296(67)$ & $147(33)$ & & $58(39)$ & $90(61)$ & \\
\hline Yes & $133(56)$ & $105(44)$ & & $44(42)$ & $61(58)$ & \\
\hline Heart conditions & & & .0001 & & & .544 \\
\hline No & $329(68)$ & $153(32)$ & & $64(42)$ & $89(58)$ & \\
\hline Yes & $100(50)$ & $99(50)$ & & $38(38)$ & $62(62)$ & \\
\hline Stroke & & & .808 & & & .011 \\
\hline No & $370(63)$ & $219(37)$ & & $82(37)$ & $138(63)$ & \\
\hline \multirow[t]{2}{*}{ Yes } & $59(64)$ & $33(36)$ & & $20(61)$ & $13(39)$ & \\
\hline & \multicolumn{2}{|c|}{ Mean (SD) } & \multicolumn{4}{|c|}{ Mean (SD) } \\
\hline Age (years: 55 to 96 ) & $71.2(8.3)$ & $72.7(8.1)$ & .019 & $69.5(7.7)$ & $74.8(7.7)$ & .0001 \\
\hline Education attainment (1 to 16 ) & $12.8(2.0)$ & $12.7(2.5)$ & .368 & $12.4(2.5)$ & $12.9(2.5)$ & .126 \\
\hline Financial strains ( 1 to 5 ) & $1.8(1.1)$ & $1.7(1.0)$ & .066 & $2.0(1.2)$ & $1.5(.8)$ & .0001 \\
\hline Continuity of care (0 to 3 ) & $2.5(0.6)$ & $2.5(0.6)$ & .789 & $2.4(0.7)$ & $2.6(.6)$ & .007 \\
\hline Major chronic conditions ( 1 to 6 ) & $1.7(1.0)$ & $2.0(0.9)$ & .0001 & $2.1(0.9)$ & $1.9(.9)$ & .273 \\
\hline
\end{tabular}

GI, gastrointestinal; SD, standard deviation.

provider increased 1.7 times (95\% CI, 1.07-2.76) when the participant reported a diagnosis of diabetes mellitus. Furthermore, participants with a history of heart conditions were 2.05 times $(95 \% \mathrm{CI}$, 1.23-3.41) more likely to receive low-dose aspirin from their providers. Comparing self-prescribed aspirin use with no aspirin use, only age and being diagnosed with heart conditions were statistically significant. The likelihood of taking self-prescribed, low-dose aspirin increased 2.41 times (95\% CI,
1.56-3.73) when the participant reported diagnoses of heart conditions. Finally, participants aged 55 to 64 years were 0.17 times (95\% CI, 0.06-0.52) less likely to self prescribe low-dose aspirin than to not use aspirin at all (Table 5).

\section{Discussion}

This study describes low-dose aspirin use among underserved middle-aged and older African- 
Table 4. Binary Logistic Regression between Independent Variables and Low-Dose Aspirin Used $(n=683)$

\begin{tabular}{|c|c|c|c|}
\hline \multirow[b]{2}{*}{ Independent Variables } & \multicolumn{2}{|c|}{$\begin{array}{c}\text { Low-Aspirin Used } \\
\text { Vs No Used } \\
\end{array}$} & \multirow[b]{2}{*}{ Sig. } \\
\hline & OR & $95 \% \mathrm{CI}$ & \\
\hline Gender & & $0.93-1.89$ & 0.121 \\
\hline Male & 1.32 & & \\
\hline Female & 1 & & \\
\hline \multicolumn{4}{|l|}{ Age, years } \\
\hline 55 to 64 (young-old) & 0.73 & $0.41-1.33$ & 0.306 \\
\hline 65 to 74 (mid-old) & 0.99 & $0.69-1.43$ & 0.972 \\
\hline$\geq 75$ (old-old) & 1 & & \\
\hline \multicolumn{4}{|l|}{ Living alone } \\
\hline No & 1.12 & $0.85-1.68$ & 0.296 \\
\hline Yes & 1 & & \\
\hline \multicolumn{4}{|l|}{ Education } \\
\hline No high school diploma & 1.02 & $0.66-1.55$ & 0.956 \\
\hline High school diploma & 0.96 & $0.66-1.39$ & 0.946 \\
\hline Some college & 1 & & 0.815 \\
\hline \multicolumn{4}{|l|}{ Smoking } \\
\hline Current smoker & 0.69 & $0.42-1.12$ & 0.266 \\
\hline Past smoker & 0.79 & $0.53-1.17$ & 0.137 \\
\hline Never smoked & 1 & & 0.24 \\
\hline $\begin{array}{l}\text { Continuity of Care (scale: } \\
0-3 \text { ) }\end{array}$ & 0.86 & $0.66-1.11$ & 0.239 \\
\hline $\begin{array}{l}\text { Financial Stress (scale: } 1 \\
\text { to } 5 \text { ) }\end{array}$ & 0.947 & $0.80-1.13$ & 0.063 \\
\hline \multicolumn{4}{|l|}{ Heart conditions } \\
\hline No & 2.24 & $1.55-3.23$ & 0.001 \\
\hline Yes & 1 & & \\
\hline \multicolumn{4}{|l|}{ Diabetes Mellitus } \\
\hline No & 1.51 & $1.07-2.14$ & 0.019 \\
\hline Yes & 1 & & \\
\hline \multicolumn{4}{|l|}{ Stroke } \\
\hline No & 0.85 & $0.53-1.40$ & 0.553 \\
\hline Yes & 1 & & \\
\hline \multicolumn{4}{|l|}{ GI conditions } \\
\hline No & 0.91 & $0.62-133$ & 0.616 \\
\hline Yes & 1 & & \\
\hline \multicolumn{4}{|l|}{$\begin{array}{l}\text { Potentially major aspirin- } \\
\text { drug interaction }\end{array}$} \\
\hline No & 0.79 & $0.70-1.41$ & 0.959 \\
\hline Yes & 1 & & \\
\hline
\end{tabular}

GI, gastrointestinal; OR, odds ratio; CI, confidence interval; Sig, Sigma.

Note: -2 Log Likelihood: 857; Sig: 0.0001; Nagelkerke: 0.080.

American adults in South Los Angeles. Our study documented a lower prevalence of aspirin use than reported in other studies, among both nonHispanic Whites and Blacks. ${ }^{31,32,42}$ For example, a recent study of a sample of well-educated African-
American adults aged 45 to 79 years, documented that $40 \%$ of participants used aspirin for a secondary $(62 \%)$ or a primary prevention $(32 \%){ }^{32}$ Furthermore, our study shows a much higher rate of self-prescribed low-dose aspirin use than national data. Using the 2017 National Health Interview Survey, O'Brien and colleagues ${ }^{43}$ documented that $23 \%$ of participants aged 40 years and older who take low-dose aspirin for primary prevention do so without their provider's recommendation. By contrast, our data show that, among participants who use low-dose aspirin, $60 \%$ do so without their provider's recommendation (ie, as self prescribed), which may reflect disparities in access to primary care among older African Americans in underresourced communities.

This study documented the following evidence that use of self- or clinician-prescribed low-dose aspirin among underserved African-American older adults might be inconsistent with the published ACC/AHA guidelines on CVD prevention: ${ }^{20} 1$ ) major aspirin-drug interactions were detected in $75 \%$ of participants who used low-dose aspirin; 2) the binary and multinomial logistic regression analyses show that major aspirin-drug interactions were not significantly different between those who took aspirin as self prescribed and those who took it as clinician prescribed; 3) no negative association between being diagnosed with GI conditions and aspirin use was detected; 4) among those who did not use aspirin, 1 out of 4 had CVD even though they could potentially benefit from taking lowdose aspirin; and 5) one third of participants aged 70 years and older with low risk of CVD were using aspirin, and $18 \%$ of them had GI-related symptoms.

Our multivariate analysis revealed that controlling for all other relevant variables, participants with diabetes mellitus and heart conditions were more likely to take clinician-prescribed, low-dose aspirin. Similarly, a recent study conducted among a sample of well-educated 684 African Americans adults ages 45 to 79 years, documented that after adjustment for demographic variables, only diabetes and hypertension remained positively associated with low-dose aspirin use. ${ }^{32}$ These findings suggests that health-care providers' recommendations and treatment plans likely, to some extent, align with current clinical guidelines regarding populations at high risk for CVD. ${ }^{1,2,44}$ However, it is important to note that our data 
Table 5. Multinomial Logistic Regression between Independent Variables and Low-Dose Aspirin Used (SelfPrescribed, Clinician-Prescribed Versus No Use $(n=683)$

\begin{tabular}{|c|c|c|c|c|c|c|}
\hline \multirow[b]{2}{*}{ Independent Variables } & \multicolumn{2}{|c|}{ Clinician Prescribed } & \multirow[b]{2}{*}{ Sig. } & \multicolumn{2}{|c|}{ Self Prescribed } & \multirow[b]{2}{*}{ Sig. } \\
\hline & OR & $95 \% \mathrm{CI}$ & & OR & $95 \%$ CI & \\
\hline Gender & & $0.80-2.12$ & 0.298 & & & 0.197 \\
\hline Male & 1.3 & & & 1.34 & $0.86-2.07$ & \\
\hline Female & 1 & & & 1 & & \\
\hline \multicolumn{7}{|l|}{ Age, years } \\
\hline 55 to 64 (young-old) & 1.88 & $0.91-3.91$ & 0.89 & 0.17 & $0.06-0.52$ & 0.002 \\
\hline 65 to 74 (mid-old) & 1.47 & $0.85-2.52$ & 0.175 & 0.81 & $0.53-1.24$ & 0.332 \\
\hline$\geq 75$ (old-old) & 1 & & & 1 & & \\
\hline \multicolumn{7}{|l|}{ Living alone } \\
\hline No & 1.57 & $0.97-2.54$ & 0.068 & 1.02 & $0.68-1.54$ & 0.91 \\
\hline Yes & 1 & & & 1 & & \\
\hline \multicolumn{7}{|l|}{ Education } \\
\hline No high school diploma & 1.58 & $0.90-2.76$ & 0.122 & 0.71 & $0.41-1.21$ & 0.208 \\
\hline High school diploma & 1.05 & $0.61-1.80$ & 0.858 & 0.89 & $0.57-1.39$ & 0.606 \\
\hline Some college & 1 & & & 1 & & \\
\hline \multicolumn{7}{|l|}{ Smoking } \\
\hline Current smoker & 0.82 & $0.42-1.57$ & 0.541 & 0.64 & $0.34-1.21$ & 0.17 \\
\hline Past smoker & 0.97 & $0.57-1.66$ & 0.908 & 0.73 & $0.45-1.17$ & 0.189 \\
\hline Never smoked & 1 & & & 1 & & \\
\hline Continuity of care (scale: $0-3$ ) & 0.72 & $0.51-1.02$ & 0.298 & 0.97 & $0.70-1.35$ & 0.864 \\
\hline Financial Stress (scale: 1 to 5 ) & 1.04 & $0.842-1.30$ & 0.063 & 0.85 & $0.67-1.09$ & 0.179 \\
\hline \multicolumn{7}{|l|}{ Heart conditions } \\
\hline No & 2.05 & $1.23-3.41$ & 0.006 & 2.41 & $1.56-3.73$ & 0.001 \\
\hline Yes & 1 & & & 1 & & \\
\hline \multicolumn{7}{|l|}{ Diabetes mellitus } \\
\hline No & 1.72 & $1.07-2.76$ & 0.027 & 1.39 & $0.92-2.11$ & 0.122 \\
\hline Yes & 1 & & & 1 & & \\
\hline \multicolumn{7}{|l|}{ Stroke } \\
\hline No & 1.4 & $0.77-2.53$ & 0.269 & 0.55 & $0.28-1.06$ & 0.075 \\
\hline Yes & 1 & & & 1 & & \\
\hline \multicolumn{7}{|l|}{ GI conditions } \\
\hline No & 0.98 & $0.58-1.63$ & 0.925 & 0.85 & $0.53-1.36$ & 0.497 \\
\hline Yes & 1 & & & 1 & & \\
\hline \multicolumn{7}{|c|}{ Potentially major aspirin-drug interaction } \\
\hline No & 1.26 & $0.76-2.10$ & 0.371 & 1.2 & $0.79-1.82$ & 0.401 \\
\hline Yes & 1 & & & & & \\
\hline
\end{tabular}

OR, odds ratio; CI, confidence interval; Sig, Sigma; GI, gastrointestinal.

The reference category is: No low-dose aspirin used; $-2 \log$ Likelihood: $1084 ; \mathrm{df}=30, \chi^{2}=09.41$, Sig: 0.0001; Nagelkerke: 0.151 .

show that even though being diagnosed with diabetes mellitus or heart conditions was associated with higher use of aspirin, only a marginally higher percentage of participants at high risk for CVD were prescribed low-dose aspirin. Fifty-six percent of participants who reported a history of diabetes mellitus and $50 \%$ of those who reported a history of heart conditions, were not using aspirin at all. This potential gap in CVD prevention care is concerning because, as is well known, African
Americans have a higher prevalence of hypertension, diabetes, and stroke compared with their agematched non-Hispanic White counterparts. ${ }^{45}$ Our finding of a racial disparity in low-dose aspirin prescription for CVD prevention is in line with other studies. For example, an examination of the inhome survey results of a large sample of older adults demonstrated widespread racial disparities of indicated preventive therapies among older adults at high CVD risk in the United States. ${ }^{46}$ 
Our data documented that a large number participants were taking low-dose aspirin despite having a potentially major aspirin-drug interaction. The higher prevalence of drug-drug interactions in the older adult population is supported by the literature. In a cross-sectional study of 3055 adults who were 70 to 79 years of age, $33 \%$ of participants had at least 1 type of drug-(non-steroidal anti-inflammatory drugs, NSAIDs) interaction, and the most common drug-drug interaction was between nonsteroidal anti-inflammatory drugs and antihypertensive medications. ${ }^{47}$ The results of our study are consistent with this finding as several of the top aspirin-drug interactions were aspirin-hydrochlorothiazide aspirin-furosemide, and aspirin-hydrochlorothiazide/ triamterene (Table 2).

Three out of 5 participants in this study who were taking aspirin as self prescribed and 1 out of 5 participants who were taking aspirin generally, had a history of GI-related conditions. Hanlon and colleagues ${ }^{47}$ also found peptic ulcer disease and use of aspirin/non-steroidal anti-inflammatory drugs to be the most common disease-drug interaction in older adults. In addition, O'Brien and colleagues ${ }^{43}$ documented that a history of peptic ulcer disease was not statistically significantly associated with lower aspirin use among a national sample of 14,328 adults aged 40 years or older. This demonstrates the need for pharmacists and health care providers to collaborate, inquire about ongoing aspirin use, and counsel patients on the benefits and harms of use, especially among older adults who might have prior peptic ulcer disease.

This study also revealed that participants that were older aged ( $\geq 75$ years) were more likely to self prescribe aspirin. This may be due to these participants' uptake of their clinician's recommendation to take low-dose aspirin to prevent CVD even though they may not have initially been given a prescription for their pharmacy records. These clinicians' recommendations would have been guided by previous evidence and clinical guidelines that conflict with the recent guidelines on aspirin for primary prevention. ${ }^{48}$ The participants in turn, would continue to take aspirin as a preventive measure although it may no longer be indicated or safe to use. Furthermore, as participants have aged and experienced changes in their primary care providers, they may be less willing to stop taking selfprescribed aspirin, regardless of whether their clinician and/or pharmacist has made or has not made the attempt to deprescribe it. This is supported by several studies that cite barriers to deprescribing as patient resistance or unwillingness to stop a medication. ${ }^{49-54}$

Overall, our data are representative of a subpopulation of aspirin use behavior and show that use of self- or clinician-prescribed low-dose aspirin among underserved African-American older adults might be inconsistent with the recently published ACC/AHA guidelines on CVD prevention. ${ }^{20}$ This is supported by other studies, which similarly suggested that aspirin use in the United States is widespread among groups at risk for harm. ${ }^{43}$ More specifically, they reported that the extent to which populations take aspirin for primary prevention in the United States is unknown. More research, specifically in African-American adults, should be conducted to reduce racial disparities in CVD outcomes. Such information may be used to design, implement, and evaluate programs that center on the clinician-pharmacist collaborative working relationship and in turn, increase aspirin use and reduce drug-drug and drug-disease interactions.

There are several limitations to this study. First, causal inferences cannot be made due to its crosssectional design. Second, recall bias was introduced into the study during the drug inventory method for medication use. More specifically, low-dose aspirin packaged in a prescription vial from a pharmacy was noted as clinician prescribed. Low-dose aspirin packaged in an OTC container prompted additional probing questions regarding whether the medication was clinician recommended. A response of "yes" categorized the aspirin as clinician prescribed and a response of "no" categorized the aspirin as self prescribed. Another limitation of this study is that the clinical guideline recommendations on low-dose aspirin changed during the 3 -year period in which the survey was conducted. This can further contribute to the perceived inconsistency regarding how aspirin is recommended and prescribed. Despite these limitations, the results contribute to the current knowledge on how aspirin is used among underserved African-American middleaged and older adults.

\section{Conclusions}

A proportion of African American middle-aged and older adults who might benefit from the 
cardioprotection of aspirin are not using it. At the same time, some African-American older adults who are being prescribed or self-prescribed lowdose aspirin may be at risk of aspirin-drug interactions. Furthermore, there is also proportion of African American individuals over the age of 70 years who are inappropriately taking aspirin and might incur an increased risk of adverse bleeding events. As such, there are great opportunities to improve the following: 1) clinician-prescribing practices of aspirin for the purpose of primary prevention of CVD; 2) clinician-pharmacist collaboration regarding comprehensive review of patients' medication regimens, and 3) patient education on the potential risks of self-prescribed aspirin use. There is a need for further studies to examine the contributions of the health care system to aspirin use behavior. Interventional studies are also needed to promote safe and effective use of low-dose aspirin among underserved African American adults.

A review of literature combined with our study show that neither non-Hispanic Whites nor minority populations, including underserved non-Hispanic Blacks, are using aspirin as safely and effectively as they should. However, underserved AfricanAmerican older adults are exposed to additional difficulties associated with health disparities. African Americans are, after all, more likely to be diagnosed with diabetes, hypertension, and heart conditions at earlier stages of life; and as a result, the role of preventive intervention, including safe and appropriate use of aspirin among this segment of our population, is more salient.

We thank Dorine Akumawah, PharmD; and Linda Opara, PharmD for analysis of examination of aspirin-drug interactions.

To see this article online, please go to: http://jabfm.org/content/ 34/1/132.full.

\section{References}

1. American Diabetes Association. 10. Cardiovascular disease and risk management: standards of medical care in diabetes-2020. Diabetes Care 2020;43: S111-S134.

2. Bibbins-Domingo K, Force U. Aspirin use for the primary prevention of cardiovascular disease and colorectal cancer: U.S. Preventive Services Task Force Recommendation Statement. Ann Intern Med 2016;164:836-45.

3. Baigent C, Blackwell L, Collins R, et al. Aspirin in the primary and secondary prevention of vascular disease: collaborative meta-analysis of individual participant data from randomised trials. Lancet 2009;373:1849-60.

4. Steering Committee of the Physicians' Health Study Research Group. Final report on the aspirin component of the ongoing Physicians' Health Study. N Engl J Med 1989;321:129-35.

5. Emilsson L, Holme Ø, Bretthauer M, et al. Systematic review with meta-analysis: the comparative effectiveness of aspirin vs. screening for colorectal cancer prevention. Aliment Pharmacol Ther 2017;45:193-204.

6. Qiao Y, Yang T, Gan Y, et al. Associations between aspirin use and the risk of cancers: a meta-analysis of observational studies. BMC Cancer 2018;18:288.

7. Sauer C, Myran D, Costentin C, et al. Effect of long-term aspirin use on the incidence of prostate cancer: a systematic review and meta-analysis. Crit Rev Oncol/Hematol 2018;132:66-75.

8. Lu L, Shi L, Zeng J, Wen Z. Aspirin as a potential modality for the chemoprevention of breast cancer: a dose-response meta-analysis of cohort studies from 857,831 participants. Oncotarget 2017; 8:40389-401.

9. Huang XZ, Chen $\mathrm{Y}, \mathrm{Wu}$ J, et al. Aspirin and non-steroidal anti-inflammatory drugs use reduce gastric cancer risk: a dose-response meta-analysis. Oncotarget 2017;8:4781-95.

10. Group ASC, Bowman L, Mafham M, et al. Effects of aspirin for primary prevention in persons with diabetes mellitus. N Engl J Med 2018;379:1529-39.

11. Gaziano JM, Brotons C, Coppolecchia R, et al. Use of aspirin to reduce risk of initial vascular events in patients at moderate risk of cardiovascular disease (ARRIVE): a randomised, double-blind, placebocontrolled trial. Lancet 2018;392:1036-46.

12. Tillman H, Johnston SC, Farrant M, et al. Risk for major hemorrhages in patients receiving clopidogrel and aspirin compared with aspirin alone after transient ischemic attack or minor ischemic stroke: a secondary analysis of the POINT randomized clinical trial. JAMA Neurol 2019;76:774-82.

13. Sugawara M, Goto Y, Yamazaki T, et al. Low-dose aspirin for primary prevention of cardiovascular events in elderly Japanese patients with atherosclerotic risk factors: subanalysis of a randomized clinical trial (JPPP-70). Am J Cardiovasc Drugs 2019; 19:299-311.

14. Lin $\mathrm{MH}$, Lee $\mathrm{CH}$, Lin $\mathrm{C}$, et al. Low-dose aspirin for the primary prevention of cardiovascular disease in diabetic individuals: a meta-analysis of randomized control trials and trial sequential analysis. J Clin Med 2019;8:609.

15. VanWormer JJ, Greenlee RT, McBride PE, et al. Aspirin for primary prevention of CVD: are the right people using it? J Fam Pract 2012;61:525-32.

16. Fernandez-Ruiz I. Aspirin for primary prevention of CVD: a matter of balance. Nat Rev Cardiol 2018;15:651. 
17. Fletcher RH. Review: aspirin for CVD primary prevention increases gastrointestinal bleeding and hemorrhagic stroke. Ann Intern Med 2016;165:JC17.

18. Luepker RV, Steffen LM, Duval S, Zantek ND, Zhou X, Hirsch AT. Population trends in aspirin use for cardiovascular disease prevention 19802009: the Minnesota Heart Survey. JAHA 2015;4: $\mathrm{e} 002320$.

19. Morgan G, Brown T. Benefits and risk of aspirin as primary prevention of cardiovascular disease. $\mathrm{ARxCH} 2019 ; 3(1)$.

20. Arnett DK, Blumenthal RS, Albert MA, et al. ACC/ AHA guideline on the primary prevention of cardiovascular disease. J Am Coll Cardiol 2019;140: e596-e646.

21. Centers for Disease Control and Prevention. Heart disease facts. 2020. Available from: https:// wwwcdcgov/heartdisease/facts.htm. Accessed July 2020.

22. Kochanek KD, Murphy SL, Xu J, Arias E. National Vital Statistics Reports - Deaths: Final Data for 2017 Volume 68, Number 9. Available from: https://www. cdc.gov/nchs/data/nvsr/nvsr68/nvsr68_09-508.pdf. Accessed November 2020.

23. Howard G, Safford MM, Moy CS, et al. Racial differences in the incidence of cardiovascular risk factors in older black and white adults. J Am Geriatr Soc 2017;65:83-90.

24. Center for Medicare \& Medicaid Services. Chronic conditions overview-Prevalence state level: all beneficiaries by race/ethnicity and age, 2007-2017. Available from: https://www.cms.gov/Research-Statistics-Dataand-Systems/Statistics-Trends-and-Reports/ChronicConditions/MCC_Main. Accessed November 2020.

25. Yazdanshenas H, Bazargan M, Smith J, Martins D, Motahari H, Orum G. Pain treatment of underserved older African Americans. J Am Geriatr Soc 2016;64:2116-21.

26. Gu Q, Burt VL, Dillon CF, Yoon S. Trends in antihypertensive medication use and blood pressure control among United States adults with hypertension. Circulation 2012;126:2105-14.

27. Kirk JK, D’Agostino RB, Jr, Bell RA, et al. Disparities in HbA1c levels between African-American and nonHispanic white adults with diabetes: a meta-analysis. Diabetes Care 2006;29:2130-6.

28. Park SY, Wilkens LR, Kolonel LN, Monroe KR, Haiman CA, Marchand LL. Exploring differences in the aspirin-colorectal cancer association by sex and race/ethnicity: the multiethnic cohort study. Cancer Epidemiol Biomarkers Prev 2017;26:162-9.

29. Sanchez DR, Diez Roux AV, Michos ED, et al. Comparison of the racial/ethnic prevalence of regular aspirin use for the primary prevention of coronary heart disease from the multi-ethnic study of atherosclerosis. Am J Cardiol 2011;107:41-6.
30. Mauer AC, Khazanov NA, Levenkova N, et al. Impact of sex, age, race, ethnicity and aspirin use on bleeding symptoms in healthy adults. J Thromb Haemost 2011;9:100-8.

31. Brown DW, Shepard D, Giles WH, Greenlund KJ, Croft JB. Racial differences in the use of aspirin: an important tool for preventing heart disease and stroke. Ethn Dis 2005;15:620-6.

32. Van't Hof JR, Duval S, Misialek JR, et al. Aspirin use for cardiovascular disease prevention in an African American population: prevalence and associations with health behavior beliefs. J Commun Health 2019;44:561-8.

33. Los Angeles County Department of Health: Office of Health Assessment and Epidemiology. Key indicators by services planning area. 2017. Available from: http://publichealth.lacounty.gov/ ha/docs/2015lachs/keyindicator/ph-kih_2017-sec \%20updated.pdf. Accessed July 2020.

34. Jianhui X, Teutsch S, Braun P, et al. The 2015 Los Angeles healthy aging report. Los Angeles, CA: USC Edward R. Roybal Institute on Aging; 2015.

35. Laaksonen E, Lallukka T, Lahelma E, et al. Economic difficulties and physical functioning in Finnish and British employees: contribution of social and behavioural factors. Eur J Public Health 2011;21:456-62.

36. Sorensen L, Stokes JA, Purdie DM, Woodward M, Roberts MS. Medication management at home: medication risk factor prevalence and inter-relationships. J Clin Pharm Ther 2006;31:485-91.

37. Bazargan M, Smith J, Movassaghi $M$, et al. Polypharmacy among underserved older African American adults. J Aging Res 2017;2017:6026358.

38. Bazargan M, Smith J, Saqib M, Helmi H, Assari S. Associations between polypharmacy, self-rated health, and depression in African American older adults; mediators and moderators. Int J Environ Res Public Health 2019;16:1574.

39. Bazargan M, Smith J, Yazdanshenas H, Movassaghi M, Martins D, Orum G. Non-adherence to medication regimens among older African-American adults. BMC Geriatr 2017;17:163.

40. International Business Machines Cop (IBM). IBM Micromedex with Watson. Available from: https:// wwwibmcom/products/micromedex-with-watson/ details. Assessed December 5, 2019.

41. Kheshti R, Aalipour M, Namazi S. A comparison of five common drug-drug interaction software programs regarding accuracy and comprehensiveness. J Res Pharm Pract 2016;5:257-63.

42. Fang J, George MG, Gindi RM, et al. Use of lowdose aspirin as secondary prevention of atherosclerotic cardiovascular disease in US adults (from the National Health Interview Survey, 2012). Am J Cardiol 2015;115:895-900. 
43. O'Brien CW, Juraschek SP, Wee CC. Prevalence of aspirin use for primary prevention of cardiovascular disease in the united states: results from the 2017 National Health Interview Survey. Ann Intern Med 2019;171:596-8.

44. Grundy SM, Stone NJ, Bailey AL, et al. 2018 AHA/ACC/AACVPR/AAPA/ABC/ACPM/ADA/ AGS/APhA/ASPC/NLA/PCNA guideline on the management of blood cholesterol: a report of the American College of Cardiology/American Heart Association Task Force on Clinical Practice Guidelines. J Am Coll Cardiol 2019;73:e285-e350.

45. Centers for Disease Control and Prevention. African American health. 2017. Available from: https://www. cdc.gov/vitalsigns/aahealth/index.html. Accessed July 2020 .

46. Qato DM, Lindau ST, Conti RM, Schumm LP, Alexander GC. Racial and ethnic disparities in cardiovascular medication use among older adults in the United States. Pharmacoepidemiol Drug Saf 2010;19:834-42.

47. Hanlon JT, Perera S, Newman AB, et al. Potential drug-drug and drug-disease interactions in wellfunctioning community-dwelling older adults. J Clin Pharm Ther 2017;42:228-33.

48. Guirguis-Blake JM, Evans CV, Senger CA, O'Connor EA, Whitlock EP. Aspirin for the primary prevention of cardiovascular events: a systematic evidence review for the US Preventive Services Task Force. Ann Intern Med 2016;164:804-13.
49. Reeve E, Wolff JL, Skehan M, Bayliss EA, Hilmer $\mathrm{SN}$, Boyd CM. Assessment of attitudes toward deprescribing in older Medicare beneficiaries in the United States. JAMA Intern Med 2018;178: 1673-80.

50. Palagyi A, Keay L, Harper J, Potter J, Lindley RI. Barricades and brick walls-A qualitative study exploring perceptions of medication use and deprescribing in long-term care. BMC Geriatr 2016;16:15.

51. Alrasheed MM, Alhawassi TM, Alanazi A, Aloudah N, Khurshid F, Alsultan M. Knowledge and willingness of physicians about deprescribing among older patients: a qualitative study. Clin Interv Aging 2018;13:1401-8.

52. Anderson K, Stowasser D, Freeman C, Scott I. Prescriber barriers and enablers to minimising potentially inappropriate medications in adults: a systematic review and thematic synthesis. BMJ Open 2014;4:e006544

53. Anderson K, Foster M, Freeman C, Luetsch K, Scott I. Negotiating "unmeasurable harm and benefit": perspectives of general practitioners and consultant pharmacists on deprescribing in the primary care setting. Qual Health Res 2017;27: 1936-47.

54. Wallis KA, Andrews A, Henderson M. Swimming against the tide: primary care physicians' views on deprescribing in everyday practice. Ann Fam Med 2017;15:341-6. 